\title{
Immersive Scholar: A Landscape Analysis of Scholarly Forms, Impacts, and Collaborations
}

\begin{abstract}
A Report Prepared by Lynnee Argabright for the North Carolina State University Libraries
\end{abstract}
Submitted October 30, 2020

*Prepared for the "Visualizing Digital Scholarship in Libraries and Learning Spaces" Andrew W. Mellon Foundation-funded project, informally known as Immersive Scholar. Learn more about this project at https://osf.io/3z7k5/wiki/home/

\section{Contents}

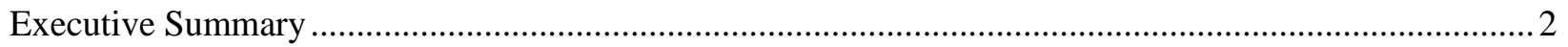

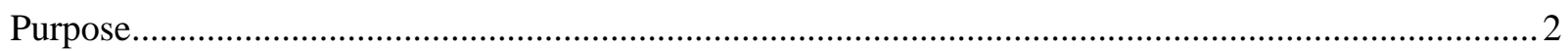

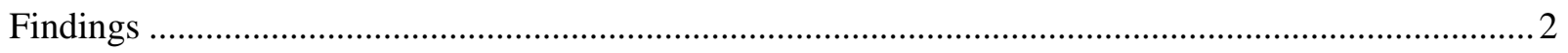

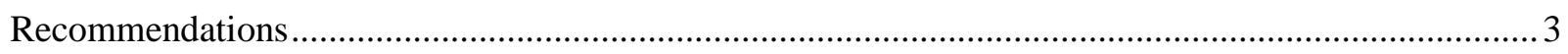

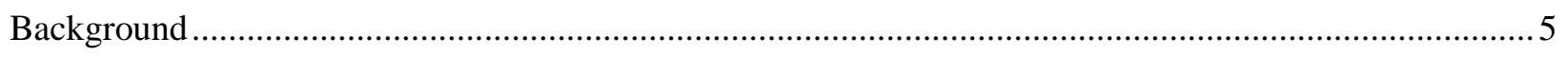

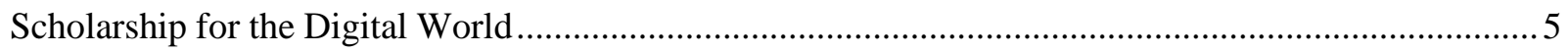

Shared Language

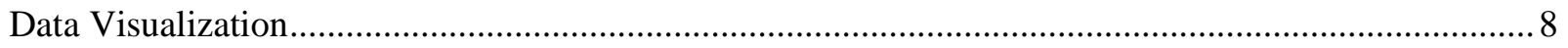

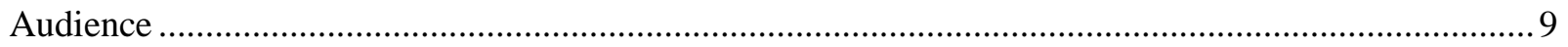

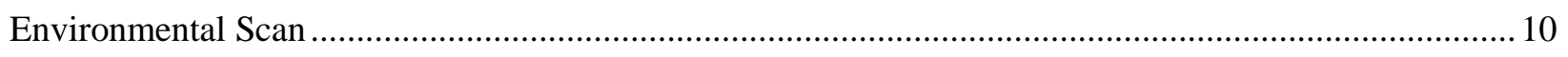

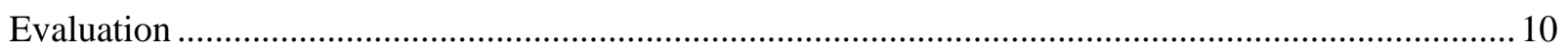

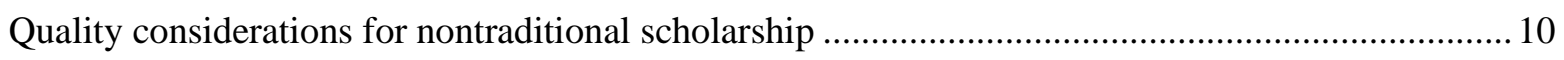

Personnel Committee considerations for nontraditional scholarship ............................................ 12

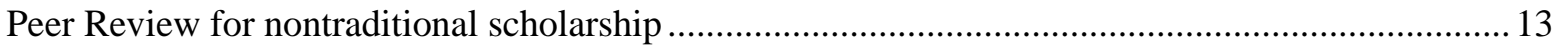

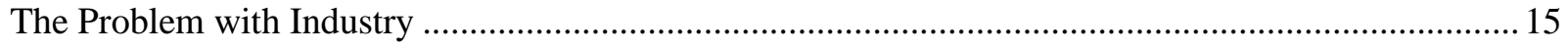

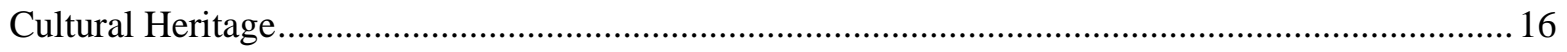

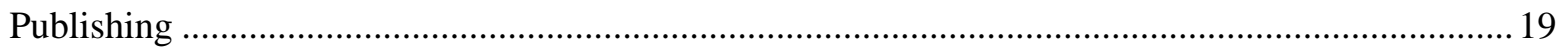

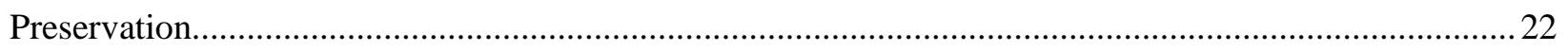

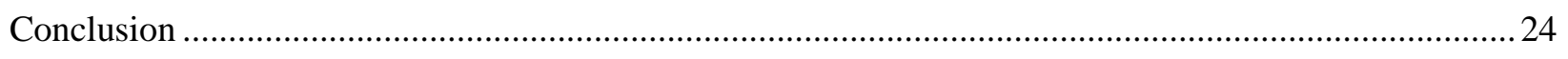

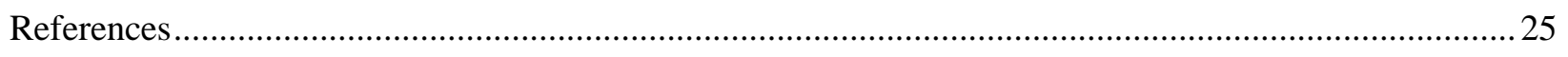

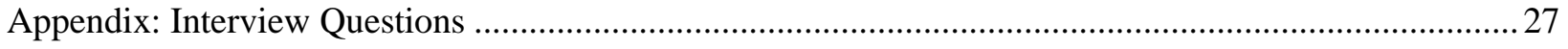




\section{Executive Summary}

\section{Purpose}

Immersive Scholar, a genre of digital scholarship that produces large scale visualizations, has emphasized physically immersive user experience. To achieve such an experience requires physical space to host the project, technology to present it, and an audience to come to view it. Immersive Scholar has been incubated within NC State Libraries in their visualization hubs, which means its scope could only reach as far as those who travel to this particular library. To disseminate Immersive Scholar projects beyond Raleigh, NC, other university libraries would need to be equipped with similar technology and space capabilities. However, as COVID-19 spread across the country, causing libraries to close their physical spaces beginning in March 2020, options for disseminating Immersive Scholar projects clearly needed to change.

Immersive Scholar has a complex market because it can be experienced as a scholarly work through the variety of formats that make up its composition - from documentation to codebase, datasets, and digital art. It utilizes software, code, data, and artistic vision, all of which are impermanent tools. It is nontextual and nonnarrative, which makes it an untraditional addition to the scholarly canon. How can it be utilized by scholars and acknowledged by personnel committees beyond just existing as a fun side project?

This report strives to meet a need that will expand its scope and impact, and identify the realms in which Immersive Scholar belong that will allow it to bring immersive and scholarly depth. It is thus intended to provide awareness about challenges and opportunities to stakeholders interested in progressing new forms of digital scholarship (in particular, Immersive Scholar). North Carolina State University Libraries engaged Lynnee Argabright over summer 2020 to conduct a landscape analysis to help foresee industry collaboration prospects for Immersive Scholar. This report will also review the current landscape of similar presentations of immersive digital scholarship as well as explore quality evaluation for tenure and review to help define assessment expectations for Immersive Scholar projects. Preservation, a core consideration of creating Immersive Scholar, will only be briefly mentioned to enforce scope, but is covered in great depth in The Socio-Technical Sustainability Roadmap (https://sites.haa.pitt.edu/sustainabilityroadmap/). Detailed economic models will also not feature in these pages in order to highlight the interplay of social processes; however, as grant funding repeatedly is associated with innovative progress of digital scholarship, economic insights are typically analyzed in these projects' annual reports.

\section{Findings}

This report was compiled through an analysis of current literature such as press releases, academic documentation, scholarly articles, blogposts, and program webpages. The literature provide examples of relevant digital scholarship and break down methods and motivations. 10 thirty-minute semi-structured interviews with professionals in libraries, museums, and university presses were also conducted. 
Participants were selected based on their current involvement with digital scholarship or on their job title to see how digital scholarship could potentially involve them. Sample questions from the interviews are provided in the Appendix.

Challenges overall are primarily due to industries having to build their innovative infrastructure while relying upon pre-existing processes and systems. This is why perspective and change can be slow and resistant. Tenure evaluation criteria do not have set metrics established for untraditional forms of scholarship, and publisher processes are built to handle textual work. Limits on staff time, skill, finances, and technological equipment reduce what is possible even if perspectives are open to change.

Among opportunities, there are already stakeholders who have begun to make changes. Funders are active in these initiatives, which enable interested parties to utilize work time to put together work procedures with others in the ecosystem. Universities are beginning to recognize at least at the department level that new roles and new technologies change the scope of what is impactful. Each change sets an example or a resource that can potentially be referenced or used by someone else.

\section{Recommendations}

\section{Remember who the audience is}

For publishers, museums, and personnel committees, knowing the audience and how the work can impact that audience is a first consideration in accepting a format such as Immersive Scholar. If they can believe in its relevance to them, they will be more likely to ask further questions.

Impact metrics change depending on audience, and so do needs criteria. Rural museums that lack the technical budget for equipment may be the best access point for some communities that could greatly benefit from Immersive Scholar knowledge. In such a case, perhaps take advantage of a containerized version (like Raspberry Pi) that requires easier maintenance of Immersive Scholar installment or that utilizes smaller, nearer key group partnerships, such as university extension offices.

\section{Begin early and communicate clearly across stakeholders}

Many different terms and responsibilities can disrupt stakeholders from identifying and moving forward on a common goal. Confusion about what or how to describe Immersive Scholar can also make the final marketing call from stakeholder sales departments vague and unclear. Figure 1 breaks down the intersecting stakeholder perspectives and how they all work together to disseminate Immersive Scholar. Instead of thinking how different everyone's goals are, they could be strengths that make the product more impactful. Partnering with other stakeholders within the scholarly ecosystem allows each stakeholder to use their own skills and insights to effectively move the project forward.

\section{Start small}

Despite a museum's size and budget, a smaller museum may be easier to initiate plans with, because they have more flexibility to make their own decisions rather than having to follow an established order of procedure within bureaucracy. When considering impact, continuous local recognition can be more valuable than a national-level side-reference. 


\section{Combat pre-existing impressions and build on what exists}

Objectness is a goal that publishers are thinking about from the beginning. When publishers think of objectness, they will think of what container will make the work possible to output. They will want to put the work into a platform, so they can release an aesthetically professional product on a maintainable and recognizable online location. Perhaps the source code that hosts the output of Immersive Scholar projects can contribute towards the release of the product on a publisher-compliant page. Using something that is already being used, like Drexel's use of Blackboard for their VRtifacts Repository, will always be an easier sell. 


\section{Background}

This section will outline some characteristics and examples of digital scholarship relevant to Immersive Scholar, show some discriminating factors between scholarship and publication, and demonstrate a need for identifying disparate audiences and terminologies amongst collaborators involved in the creation of digital scholarship.

\section{Scholarship for the Digital World}

Digital scholarship uses various digital tools to engage users with the research uniquely. These projects, such as digital humanities projects, can expand the reach of the research, enabling discussion and participation amidst and beyond the academy about the research. Transforming the project into a digital publication involves a third party, typically a publisher, to move it through a series of peer review and production processes so as to be considered an authoritative, consolidated work. This suggests that digital scholarship alone, without a publisher, can be a definitional pandora's box: unreviewed quality, potentially a singular dataset. In order to follow a set of procedures involved in the publication process, a digital publication, conversely, has historically been primarily a standardized monographic form with supporting multimedia elements that play a similar role to static figures beside text. But this has the right to expand, depending on the demand for the digital project or the priority of the publisher. As reviewed in the 2007 report University Publishing in the Digital Age, "The second stage of the transformation-the creation of new product types enabled by digital technologies - has just begun. New publishing models are emerging in response to demand for real-time dissemination, dynamic material, more collaborative research and authoring environments, and usage of rich media. (Griffiths, 2007, as cited in Albers, 2017). The fact that this was being discussed in 2007 and yet digital publications are still primarily published in text-focused form suggests that perhaps more third parties besides publishers need to get involved to expand these models of technological research.

Donald J. Waters highlighted nine features for monographs to transition into a modern digital market (Waters, 2016); these would enable generations of researchers used to researching online to retrieve the information despite the scholarship's monographic form:

- interactive and searchable

- portable across reader applications

- capable of supporting metrics of use while respecting privacy

- maintained and preserved in its digital form

- economically sustainable

- peer reviewed

- supports user annotations independent of any particular reader technology

- reviewed and eligible for disciplinary awards

- expertly marketed, accessible, and owned (not rented) by the reader.

Though digital scholarship projects, such as Immersive Scholar, must not necessarily include text, many of these features still seem relevant for consideration. A publisher must find some economically sustainable method to continue publishing these types of projects, though the diversity of technical 
requirements and maintenance may impose more expense than a standard monographic format. In accordance with the many responsibilities of publishers, marketing and publicity can increase the discoverability of the digital scholarship project. Peer review of the contents and the format provides authority to the trustworthiness of the research — as discussed in the "Peer Review" section, the peer review process, including the questions asked of reviewers, can have flexibility depending on the needs of the project. The presentation and hosting of a digital scholarship project, like for a digital monograph, should also be adjusted for its digital audiences. As distinguished from monograph formats, digital scholarship projects can sometimes be construed as curation in online environments - that is, information is selected based on a particular argument(s)--so being interactive and searchable through tagged metadata is still vital to retrieve appropriate information. As discussed in the "Publishing" section, however, diverse metadata schemas may need to be applied for specific unusual digital projects, and may not crosswalk to other search indexes as comprehensively.

The Association of American University Presses (AAUP) created a list of over eighty digital publishing projects and initiatives by university press publishers (http://www.www.aaupnet.org/aaupmembers/news-from-the-membership/digital-projects-directory). Most of these are online databases of the publishers' ebooks and journals, and digitized or born-digital monographs. But, in one case, the publisher produced a book as well as hosted a catalog record for an Apple iPad app to view and interact with the book's color palette content (http://yupnet.org/interactionofcolor/); though Yale University Press had to partner with and host software material, this engagement method is clearly considered a supplement to the text rather than standalone scholarship.

AAUP has also been maintaining a list of university presses who have collaborated or made progress to the emerging digital scholarship model (http://www.www.aaupnet.org/aaup-members/news-from-themembership/collaborative-publishing-initiatives). Most of these are made possible due to grants. Some publisher efforts include:

- A digital scholarship product from University of Michigan Press published in 2019 to Fulcrum entitled ESC: Sonic Adventure in the Anthropocene (https://doi.org/10.3998/mpub.10120795). Rather than text, the near entirety of this scholarship is instead podcast-like audio files, and academically combines "sound studies, radio history, and environmental criticism."

- UNC Press created a traditional print monograph as well as an alternate digital version posted on Fulcrum, which included GIS maps and images - both were marked as "published" by UNC Press. The press's Board of Governors, which approves all manuscripts before publication in order to use UNC Press's brand, was only interested in the peer review reports of the manuscript scholarship and held little curiosity for assets possible in the companion digital version.

- Co-publishers, Emory University's Center for Digital Scholarship and UNC Press, will produce the NEH funded Sounding Spirit publication (https://soundingspirit.org/). It will be produced digitally on Readux to include annotated facsimile collections of 1850-1925 era songbooks and texts about the music. While Emory is conducting the peer review, UNC Press had to approve the questions. The library is a key partner to the project, which was vital to the decision of the UNC Press Board of Governors to approve the quality.

- Stanford University Press, through a Mellon grant, has developed a platform for digital-born scholarship (https://www.sup.org/digital/), and in doing so has been setting a cost-basis for publishing digital objects and establish an example of publishing practices (such as technical 
documentation http://blog.supdigital.org/tag/technical-guidelines) that other publishers can emulate, adopt, or adapt.

- Publishing Without Walls (http://publishingwithoutwalls.illinois.edu/), funded by the Mellon Foundation, is led by University of Illinois Library and is in partnership with the Illinois Program for Research in the Humanities and various university presses (University of Illinois Press, University of Michigan Press, University of Minnesota Press) to create multimedia projects. It describes that it helps build publishing models that can be supported locally by a university's library and also bridges relationships to publishers. The publication tools and platforms they use are still standard to textual works: including Open Monograph Press, Open Journal System, Omeka, Scalar, Pressbooks, and Wordpress. Their solution for preserving includes keeping a simplified version as well as the raw machine-readable code, in efforts to recreate the product through software emulation. The webpage for this funded project seems to be last updated in 2017.

- Though not a publisher, Drexel University initiated the creation of an online database called VRtifacts of VR and AR images, 3-D objects, and 360 degree panoramas (Lieberman, 2018). It will be hosted on their LMS, Blackboard, for the purposes of using for teaching. Usage metrics such as number of users and downloads can be pulled from Blackboard. Faculty will be able to submit content for approval by the site's university administrator, and rate and comment on content. This was possible due to a partnership with industry to create and maintain the repository.

At their core, scholarly publications need discoverability, longevity, and objectness (Albers, 2017), something that many individual digital projects produced by scholars lack without others to support them in these pillars. The idea of objectness includes:

- a sense of permanence and stability

- clear boundaries set within the product as part of and associated to the site

- clarity for questions such as "What is this thing I am in? Where does it start and stop? Who is responsible for it? What rules does it follow, such as for navigation and updates? And what position does it have relative to other 'objects', such as other online catalogues, museum collection pages, exhibition websites, and so on?"

- accessible and transparent user interface, such as open source files and GitHub version control.

As Albers (2017) notes, "It is not enough to simply declare something to be a book. 'Ceci n'est pas une pipe." The audience must see these pillars satisfied to even begin to trust and utilize the product... and this means any stakeholder partner producing the project must first consider the project capable of succeeding in these pillars.

\section{Shared Language}

The terminology for "digital scholarship" itself is highly varied, making efforts to define, support, and produce digital scholarship feel siloed. Alternative terms include: digital work, digital publications, scholarly digital outputs, scholarly digital initiatives, multimodal work, multimedia projects, digital media, digital archive, and new media. A standardized term rather than informal descriptive language like these listed would help to assemble similar formats of digital scholarship, so that the genre could become 
familiarized and expanded upon. Ironically, as the extent of what qualifies as digital scholarship is continually experimented with due to the broad options increasingly available in research technology, no one uniform term seems descriptively appropriate. Subsectors within digital scholarship include: digital monographs, digital humanities, virtual reality, digital exhibitions, and data art. These subsectors can substantially determine the reach and choice of audience, even if their aim were the same.

Collaboration to produce work will also struggle if different terminology is used to describe something similar. Throughout the interviews and analysis of resources for this report, different industries involved with digital scholarship referred to the objects and the responsibilities differently. Museums used words such as objects, materials, and works ("works" specifically for fine art in art museums). All works the museum owned ("accessioned") were part of their overall collection, and a selected grouping of works they owned or loaned that they wanted to highlight were on display as an exhibit. Publishers used words such as the name of the product's format, such as an online resource or book; manuscripts, and projects. All works they owned ("acquired") were part of their catalog, and a distinct discipline of works were separated as a list — the current year's list being a "frontlist" and the historic years' lists being the "backlist." Libraries used words such as digital works and research projects, referring to all those they provided support for (did not own) or partnered on as a list of projects. The importance of all the many elements involved in producing a digital scholarship project - for instance, market research on its financial comparability, peer review on its authority, marketing for its discoverability, interoperability for its shareability, preservation for its longevity, documentation for its reproducibility - is not always obvious if the aim of an individual industry only encompasses part of the project's research lifecycle. The libraries care heavily about interoperability so that the work can be ingested onto and found on multiple platforms, whereas the museums are likely to only care about its success on their own platform as they want to bring in audiences to their own site. Meanwhile, publishers rely on librarians to create metadata for their products' discoverability, and only recently have a few begun to hire their own discovery specialists (with varying job titles), according to Abigail Wickes, a former Senior Analyst for Library \& Discovery Information in Institutional Marketing at Oxford University Press. Some rudimentary goals must be clear and shared.

\section{Data Visualization}

So how do the large scale visualization qualities of Immersive Scholar fall as a scholarly product? According to Jarreau (2020), visualization projects can:

- initiate interdisciplinary collaboration

- create impact into broader audiences

- articulate complex findings

- empower participation with and build-off points from the research completed

- attract funders that focus on broader impacts and science communication

- garner critical reception such as from news media

- enhance classroom learning

Tableau blogger Ben Jones refers to data visualization in which “'[F]orm' (how it looks - or, aesthetics) and 'fit' (how it matches reality - or, clarity) combine to produce some 'function' (an intended effect or, impact)" (Jones, 2012). Singular data visualizations typically do not themselves qualify as tenure 
portfolio worthy but rather as supporting figures of some larger work. Scholarly efforts among fellows and professional associations related to visualization has been working to highlight visualization as an impactful research product (for example, the IMLS-funded Visualizing the Future library instruction projects https://visualizingthefuture.github.io). But as visual products, they enhance the understanding of and engagement with research, rather than the data remaining invisible (Williams, 2017). Engaged reception to a broader audience is a valuable goal of public scholarship in university evaluation criteria already, and creative works like aesthetic visualizations are increasingly outlined in criteria of art and literature departments at universities.

Data art has become a medium of artistic expression for artists and a useful strategic tool for industries. Maxence Grugier's blogpost on Techcrunch explains how data art began as one way to present big data information and provides some examples of data art (https://techcrunch.com/2016/05/08/the-digital-ageof-data-art/). One data art studio worked with industries to create a visualization to show their structural representation beyond a typical org chart, to show insights about how units relate to each other, which can help with managing others and determining a strategic vision. The artist points out that for a complex or dense dataset, a data visualization can be limited in its ability to singly indicate all the information while still remaining interpretable (Benzi, 2020); accordingly, textual narrative for analysis to explain the data for a standard research publication format does not always do the data justice or show appropriate scope. Data art, as an alternative, can provide a better sense of the information because it is does not have to be as technically precise. Retrieving the technical details can still be found through documenting the methods of creating the art and sharing the raw data. As a bonus, data art creates a fresh perspective that can depict an essence beneath the data, such as emotion, for a richer engagement.

Science and art can be used in collaboration to enhance scientific understanding - as far as science communication goes, "Collaborating with artists helps scientists to see their own work in a new light. These collaborations can spark insight and inspire scientific creativity, spurring scientists to test new hypotheses and consider novel interpretations of their findings. ... Without art, science lands flat" (Jarreau, 2020). As one institutional example, CERN initiated Collide, an art residency (https://arts.cern/programme/collide), in 2011 and later partnered with the Foundation for Art and Creative Technology (FACT) to produce and exhibit the residents' artistic works (https://www.fact.co.uk/fact-together\#artworks). As the FACT director states, "We need voices from the arts and sociocultural disciplines to provoke important debates" (Williams, 2017).

\section{Audience}

Digital scholarship such as Immersive Scholar projects have the opportunity to attract interest from a variety of audiences based on their distinct needs criteria. As the personnel committees question the impact of a work, recognizing the audience to which the work is impacting is significant. Who will use this work? Likewise, when considering how to produce and disseminate this work so that it can reach audiences, recognizing which industry can help to reach the audience will expand the likelihood to reach and impact. In McCarthy (2019)'s mixed methods study, the Gardens, Libraries and Museums of Oxford identified six audience personas that visited their organization (Figure 1 in E. McCarthy, 2019): Engaged Explorers, Facilitators, Producers, Conforming Learners, Cultural Consumers, and Escapists. Between four museums of various types, a botanic garden and arboretum, and 28 libraries within the Bodleian Libraries system, the institutions collectively attract over three million physical and six million digital 
visitors. They wanted to know why visitors came; knowing only who is coming based on demographics "yield[s] a false sense of explanation" (Falk, 2016, as quoted in McCarthy, 2019), whereas knowing them based on their motivations can help to "think about what types of projects or work we might put into engaging each type of visitor and where." Creating a set of personas to understand an institution's audience can help to implement a digital strategy for dissemination.

It is our belief that Immersive Scholar projects share many similar audiences to those personas identified in McCarthy's study. Displaying these projects through a faculty's webpage provides limited views, and displaying through the library will engage only those who have already sought the library. In addition to striving to build credibility to these works to support faculty tenure and promotion portfolios, partnering with industries in other areas of scholarly ecosystem can gain the skills of these industries and the dissemination power to reach more of these audiences.

\section{Environmental Scan}

This section will first review impact metrics and tenure review procedures related to digital scholarship. It is intended primarily to support creators as they prepare for tenure review, but personnel committee members can also use this to reflect upon how they should shape their committee decisions and prepare upcoming faculty. This section will then look at processes and motivations within two industries, museums and university press publishers, to highlight potential opportunities and challenges related to collaboration prospects for Immersive Scholar projects.

\section{Evaluation}

Scholars preparing for tenure review need to feel trust in being able to prove impact or else they may not feel incentivized to put in the effort that would go into a digital project. Dr. Chris Harrison is one researcher who could have received more specific credit for his efforts had evaluation criteria supported his expanded forms of scholarship: He has done a tremendous amount of research projects as depicted through information visualization. Unfortunately, as his personal website (https://chrisharrison.net/index.php) depicts, he views these projects as supplemental, placing them within a "Fun Projects" tab and incorporating the visualizations, the museum exhibitions, and the news articles about his work, in a self-annotated "Supplemental" header of his CV.

Peer review as a form of vetting, in addition to other trustworthy metrics, would help the tenure committee to recognize a level of quality similar enough to translate to the publication of a traditional academic book, but in some cases, individual departments may be bound to judge only specific formats outlined in their evaluation criteria. This will require discussions amongst faculty about supporting crediting expanded forms of engaged scholarship. Dr. Abby Mann provides additional documentation and best practices for supporting new forms of scholarship, including evaluation methodologies, labor, and peer review (https://osf.io/ygcn2/wiki/home/).

\section{Quality considerations for nontraditional scholarship}

Tenure and review is a long-prepared-for outcome for scholars employed by universities, and digital scholarship is generally not covered explicitly for research formats in university tenure documentation. Due to the visual, often generative nature of Immersive Scholar projects, accepted demonstrations of 
value may show similarity to those within performative and creative departments. According to Rutgers's Visual, Media, and Performing Arts department, accomplishment can be demonstrated through "performance, publication or exhibition in professionally recognized settings, usually outside the University. The artist's work shall have an intrinsic value equal to scholarship and shall be subject to equally rigorous evaluation" (Rutgers University, n.d.). Thus, to deem quality, some form or alternative to peer review must therefore exist. College Art Association details some types of peer-reviewed exhibitions, such as juried shows, curated and invitational shows, and artists' coops or professional societies (https://www.collegeart.org/standards-and-guidelines/guidelines/statement-of-exhibitionvenues). According to University of South Florida's School of Theatre and Dance, qualitative value can be indicated through "regional, national or international recognition of the venue, company or university . .. critical recognition, awards, or honors received; size and scope of the creative work; the level of involvement/ size of contribution to the creative work; appearance of images, examples or discussion of creative work in print and digital media" (University of South Florida, n.d.). This could potentially include an Immersive Scholar exhibition within a museum, news or events held following the release, and proof of planned growth of the project.

Identifying impact for nontraditional works is more challenging when traditional citation metrics do not apply. And with more artistic and performative work, metrics can often be considered subjective or less important due to their relationship to entertainment rather than scholarship. Depending on the audience, impact metrics are different: artistic producers cared about the quality of production according to their objectives; artists cared about technical articulation and contribution to the art form, and public audiences cared about emotional response (Bunting, 2007, as cited in Gilmore et al, 2017). As art can be impactful to the public, to the peer (other artists, other scholars), and to the individual, value for public funding, and for university institution, impact should be assessed in regards to all of these. Various arts sector organizations have worked to develop frameworks that measure quality and impact of art activities, pulling out eight identifying measures: relevance, captivation, originality, distinctiveness, national and global excellence, risk, and rigor (Chappell \& Knell, 2012, as cited in Gilmore et al, 2017). In Australia, a group of professors set up and trialed Culture Counts, an evaluation system for art that compiles information from various stakeholder types and triangulates the metrics. By following a standardized, internationally recognized metrics system for art, measuring quality becomes less subjective to the individual and more comparable against other organizations' works - in addition to spreading a shared terminology across stakeholders.

Visual or generative scholarship must be recognized as a temporal form. Video recordings can provide evidence of the work, but to represent the intention of immersivity, evaluation should include responses during and after the product's creation. This could resemble dance and theatre documentation: "Where feasible, qualified viewers of production work and performances will be asked to write evaluation statements concerning specific aspects of the creative product. Similarly, recognized experts in the field who have the opportunity to observe the ongoing process of creative projects will be asked to offer assessments. Faculty are urged to submit succinct written narratives about their creative process in production" (University of South Florida, n.d.). 


\section{Personnel Committee considerations for nontraditional scholarship}

Tenure committees place a lot of consideration on the external reviewer's response, because it provides a perspective that can show how the candidate's impact has spread beyond their department. Because of the nature of untraditional scholarship, it is harder to find an external reviewer who can speak about their interaction with and their view of the impact of a person's untraditional work. Traditionally, an outside reviewer is a tenured professor in a relevant discipline at a peer institution and are selected because they have some familiarity with the person's work in some way. For a person to have created Immersive Scholar types of work, a relevant external reviewer could be a well-known curator-someone not within academia — or someone expert in the digital methods used, for example. Many professional associations reportedly compile a list of scholars who have digital and public interest comfort, such as American Anthropological Association (https://www.americananthro.org/AdvanceYourCareer/Content.aspx?ItemNumber=1644). Artistic or performance departments' candidates with experiential contributions likely have atypical external reviewers, so these could be representative when recommending external reviewers. Challengingly, a non-academic external reviewer would need to understand why they were being asked to respond to the personnel committee and recognize in what ways the work has overlapped in its impactful contributions to society and scholars, so providing clear questions for them to refer to would help them connect scholarly value. Considering the committee's weight on the reviewer's response, the untraditional work would need a sufficient emphasis on its potential for scholarship for it to become an asset in the person's evaluation.

Tenure review documentation itself is not frequently revised, but discussions about expanding breadth within the evaluation criteria need to be begun and normalized within departments. As one Chronicle of Higher Education article states, innovative scholarship forms are tricky but important to integrate into tenure track discussions (Fitzpatrick, 2011). Top-down methods obviously move forward such progressfor example, Duke University's Provost stated in the 2017 strategic plan that evaluation documentation needs to redefine forms of scholarship to account for increasing ways to communicate scholarship, especially through emerging technology. Following thereafter, Duke's Tenure Standards Committee created rubrics to evaluate innovative scholarship and described how to choose evaluators and how to outreach across the university (https://strategicplan.duke.edu/wp-content/uploads/sites/15/2018/11/TSCreport-final-May-2018.pdf). However, individual candidates or their mentors can begin the conversations at their department level. As a scholar argued to her university's tenure committee about digital humanities, "By counting a professor's development of a platform as research, we legitimize as scholarship building software to promote the activities of citizen scholars in the ways that humanists see as valuable" (Mandell, 2012). There are various sources that provide templated language, case studies of tenure criteria at other universities, and recommended information to present to the committee, including Journal of Digital Humanities, 1(4) from 2012 (http://journalofdigitalhumanities.org/1-4/documenting-anew-media-case-evaluation-wiki-from-the-mla/) and University of Florida's Digital Humanities Working Group (https://digitalhumanities.group.ufl.edu/dh-uf/tenure-promotion/).

A department's expectations on impact criteria may fluidly expand as it hires more types of faculty, whose specialties may require more variation when it comes to evaluation--- for instance, the addition of a "Clinical Professor" as a job title must include the idea of what "practice" means for a faculty member, which essentially will broaden what role a professor plays and how it ties to value. According to Dr. 
Stephanie Haas, 2019-2020 Personnel Committee chair at UNC-Chapel Hill School Information and Library Science, defining what counts as quality is often determined on a case-by-case basis as a withincommittee decision. A good tenure committee will have discussions years prior to someone coming up for review to think about what that person's type of work means for scholarship. This helps the senior scholars in the department to guide the junior scholar on how to prepare for their review and impactfully practice their form of scholarship without getting in trouble. An unprepared junior scholar with an untraditional scholarship may not advantageously have done anything with their work, and an uninformed committee will not have thought about how value may need to be defined adaptively.

To influence a committee to be more open to untraditional works, collaboration among departments, often through the venue of overlapping university centers, can naturally expand what scholarship is possible and alters what format may best depict that scholarship. Also, revolving the participation of members in the personnel committee, so that it includes junior faculty, can bring in fresh perspectives about interpreting scholarly work as well as help junior faculty learn how to shape their own scholarship.

Besides traditional metrics, the committee can view other ways to understand impact. Untraditional work may involve a discussion of grants, which are already a recognizable form of impact. Dr. Stephanie Haas from UNC-Chapel Hill expands upon what she looks for in a tenure review portfolio regarding alternative metrics: If the candidate received a grant, how are they using it and what collaborations have they formed because of it? If the person applied but did not get a grant, what do they plan to do next and what did they learn from the comments? Also, if the candidate built a community around this new type of object or information, how did the person contribute to the community? This helps to see how the work matters to others and shows what audience is now reachable because of the work. Providing byproducts or samples of the project, such as demonstration videos posted on Youtube or code posted on GitHub, can give the committee usable metrics, such as the number of views, the variety of domains (i.e., not all coming from an .edu affiliation) and geo-locations that viewed it, and the number of forks for reusing code. Similarly, reviewing intended audiences of the work that cited the person's work (for instance, visualizations for white papers) can suggest the reusable impact of the original work.

\section{Peer Review for nontraditional scholarship}

As repeatedly brought up throughout this report's collected interviews and literature sources, an esteemed scholarly product is expected to have peer review. To bear an imprint from a university press, peer review ensures the work aligns with the press's mission. The timing and process itself of peer review has some amount of flexibility. For traditional journals, the editor of the journal often conducts the peer review, and the publisher facilitates it. For traditional and digital monographs, the publisher conducts the peer review to check on whether to acquire it or whether to request revisions before accepting the manuscript. Less traditional formats need flexibility, though publishers used to traditional formats bear some uncertainty about the quality of peer review if they are not handling it themselves. According to American Association of University Presses (2016), though, the "dynamism of [scholarly digital initiatives] requires ongoing assessment of conventional peer review processes." Box 1 contains the set of peer review questions specially designed to address quality of innovative features for an untraditional project. 


\section{Digital Project Peer Review Questions}

1. In your own words, what is this project about?

2. How would you rate the scholarship of this work? Is there either something "new" here or at least a synthesis of literatures and arguments that will render the project different from other projects?

3. Do you know of other digital projects that are similar to this one? Please describe their merits relative to this one.

4. Is this presentation of the scholarship uniquely suited to a web-based medium?

5. What kind of readers do you think this project will appeal to? Could it be used in a classroom and, if so, in what fields and at what level should it be used? Do you think the general public would be interested in this project?

6. Do you have any comments or suggestions about the presentation style or organization of the project?

7. Please comment on the usability of the site. Is the navigation intuitive and appealing? Are the features user-friendly?-Do the interactive and the descriptive elements complement each other? Should they be treated differently?

8. Are there topics on which you feel the author spends insufficient time? Is there anything on which the author dwells too deeply? Do you have any suggestions for further materials or resources the author could include?

9. Would you recommend this project to students and colleagues?

10. Is there anything else you would like to say about this project?

Box 1: Peer review questions for 2016 Scalar monograph Phantom Skies and Shifting Ground (Source: Sara Cohen, Temple University Press)

Multimodal projects may be assigned an editorial board to guide through publication development, and technical experts may be reached out to for review in addition to content experts to evaluate fit for its varying audiences. At University of Michigan Press, the Book Unbound book project (https://blog.press.umich.edu/2017/08/u-m-humanities-collaboratory-book-unbound-project-digitalpublication-humanities/), one of three digital publications funded by University of Michigan's Humanities Collaborative has been granted by the university press's faculty executive committee an adapted form of peer review. To avoid anonymous reviewer discomfort about the unnatural nature of the works, it was agreed to keep the peer review within the university, including a member of the press's faculty executive committee, the digital scholarship strategist at the university library, and members of the Humanities Collaboratory. Setting up a select committee of peer reviewers for Immersive Scholar projects, similar to the "Book Unbound," may engender willingness and understanding to review for the quality of the scholarly content, the technological analysis, and the artistic experience. Such committee members could come from NC State or the Research Triangle, with a diverse cast of background discipline expertise.

Finding peer reviewers is challenging for "sites that often felt ephemeral, non-scholarly and totally lacking the packaged authority of a traditionally published print volume," because the format is unfamiliar and automatically generates skepticism and discomfort. Art Libraries Society of North America (ARLIS) has actually begun a journal called ARLIS/NA Multimedia \& Technology Reviews (https://arlisna.org/publications/multimedia-technology-reviews/) specifically to assess digital technology and platforms of art scholarship and research. Institut fuer Dokumentologie und Editorik's journal called $R I D E$ (https://ride.i-d-e.de/) is doing this, too, and has a wishlist of digital projects for peer reviewers to 
volunteer for. Therefore, if a digital project is referenced in review journals such as these, that could essentially be one form of peer review for the project.

\section{The Problem with Industry}

In Immersive Scholar, the library has been heavily involved in supporting the creation of the experiential scholarly work - but it is interested in seeking partnerships to further the extent and credibility of this scholarship genre. As Johanna Drucker (2009) notes in a Chronicle of Higher Education article, "The library is a crucial partner in planning and envisioning the future of preserving, using, even creating scholarly resources. So are the technology professionals. But in an analogy with building construction, they are the architect and contractor" (as cited in Svensson, 2016). Industries are shifting their missions and responsibilities due to the pressure of changing technology capabilities for research. In Figure 1, various industries within an Immersive Scholar digital scholarship ecosystem are highlighted with potential areas for collaboration, and with external industries tacking on expectations that must be met.

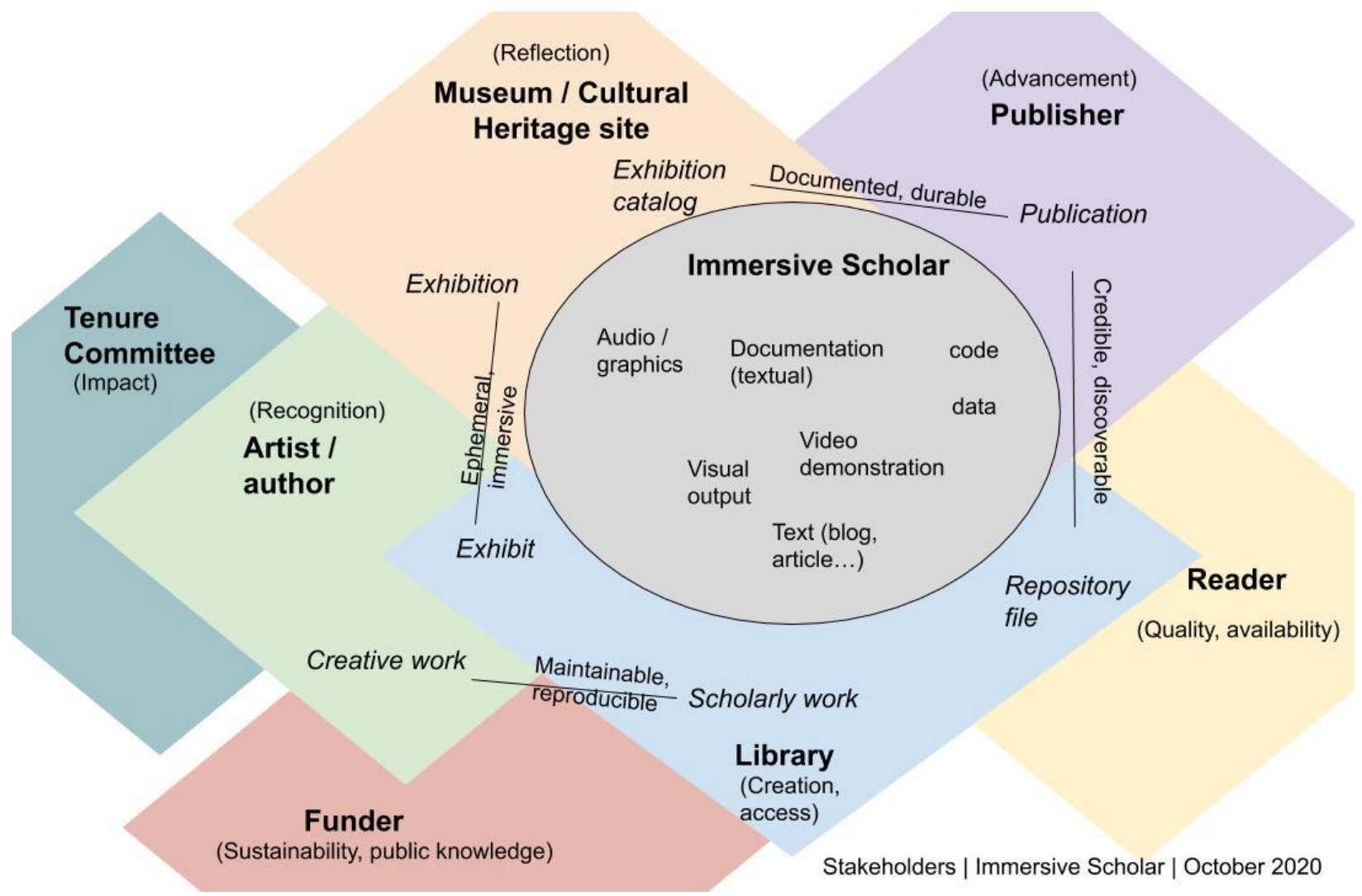

Figure 1: Diagram of overlapping areas and responsibilities in the Immersive Scholar Ecosystem (Credit: Lynnee Argabright)

Figure 1 shows overlap between and involvement within various stakeholders of Immersive Scholar. Noted within the Immersive Scholar circle in the center are the oututs and file types that comprise the content of an Immersive Scholar product. Three stakeholder industries have promising overlap on the creation of Immersive Scholar projects: museums, publishers, and libraries. They will each need to consider how to work with these file type contents to successfully produce and manage the work. Other 
likely stakeholders relevant to Immersive Scholar are the artists, who research and create the work; the tenure committee, whose judgement the artist must consider when creating the work; the funder, whose grants enable the artist to develop the work; and the reader, whose own research needs cause the Immersive Scholar product to be used and impactful. Within each stakeholder group is an overarching goal motivating their relationship to Immersive Scholar, contained within parentheses. For the museum, publisher, library, and artist who are involved in the physical creation of the product, the action in which they are involved is noted in italics. For any of these actions that contain similar responsibilities across separate stakeholders, a line is drawn between the two; terminology that describes a shared characteristic between these similar actions is written along these lines.

\section{Cultural Heritage}

Due to Immersive Scholar's experiential output, we have considered fit within cultural memory institutions, such as museums, university special collections, and archives. These institutions emphasize their collections, which make them recognized uniquely as valuable assets to the community. Exhibitions in particular are what enables elements of the collection to be showcased. If cultural institutions are to become partners, the visual output of Immersive Scholar projects could be displayed as a digital object within an exhibit, or as a digital exhibition itself.

Partnerships between academic libraries and museums have occurred due to the museum collection's likely resonance with library visitor experiences, the relevant research and data available to use in combination at the library, and the combined skills of museum and library staff. For example, the Williams College Library and the Williams College Museum of Art developed a partnership from a 2016 Mellon grant, to produce the WCMA Explorer (http://wcma-explorer.williams.edu/). The museum got metadata and user experience support from the library to help make the museum's collection data accessible on an online interface. This project would allow teachers to discover what museum materials could be appropriate to help illustrate concepts and set up activities within their courses. It also would utilize the collection records to enable data visualizations about individual materials against the collection as a whole (Levulis, 2016). Finally, the metadata itself is released on GitHub for anyone to access (https://github.com/wcmaart/collection). Though the project itself is intended as a tool to better utilize the collection, the collaboration shows a common goal that could translate to Immersive Scholar projects. Certain questions to keep in mind when seeking partnerships include: Why does each stakeholder care? Who is the intended audience and how does the project fit within how the stakeholder supports that audience? Why is each stakeholder's skills needed to be involved? Which stakeholder leads the project? For Immersive Scholar projects, the library could get involved with facilitating a partnership between the artist and the museum to produce a packaged product ready for the museum's use.

\section{Accessioning}

The accessioning and preserving processes for digital works are considered separately. This alone will make creating documentation, such as a manual of parts, installation, and maintenance, all the more important, as the technologist will have to deal with what the curator has chosen to accession. The museum will expect to receive a final product, which includes whatever hardware, software, and files are needed to run the output. Lozano-Hemmer (2015) details a list of material that should be submitted to the museum, including a written manual describing and picturing conditions of the object and how to install it. Typically included in an artist's contract with the museum should include what happens (i.e., whose 
responsibility to fix) if the digital object fails. Lozano-Hemmer recommends the artist stipulate an upgrade fee so that the artist can come upgrade the object to a new version if any of its technology becomes antiquated (Lozano-Hemmer, 2015). Considering that the museum does spend money on accessioning the object, it's in the museum's interest to ensure that the object can and will be maintained. Most museums will not have the internal expertise to fix the object itself. Regarding preservation, interactive works likely require elements to be preserved separately. Must a computer with legacy software that runs the data be maintained to ensure the object can continually run, or is a static representation of it acceptable?

\section{Exhibiting}

Including Immersive Scholar projects within museum exhibits allow audiences to engage in the ephemeral experience of the work. Museums care greatly about the user journey. Exhibits that contain digital formats can be artist-commissioned or vendor-commissioned, depending on the purpose of the exhibition to be as works of art in themselves or as educational or collection-depicting. As Chad Weinard, a Museum Experience Consultant and Strategist, explains, if the exhibit is artist-led, the artist's creative vision is given a lot of space, and their work is typically accessioned by the museum. The Immersive Scholar projects resemble artist-led exhibits, as these are imagined and created by an artist. If the artist involved the museum during the creation phase of the project, they could consciously set up the work to be properly suitable for the technical, logistical, and physical requirements of the museum, and ensure both the artist and museum's goals align in the project's theme. It is important to note that exhibitions can take years to put together, so contacting a local museum early on in a digital project's creation may earn more project and timeline flexibility and more willingness to collaborate than a larger organization layered in bureaucracy. With their smaller bandwidth, however, a library may need to do more of the work involved in project and exhibition creation.

Another notable point is that museums have specializations to their collections. When considering partnerships, consider what type of museum would be most appropriate to the project's focus. For example, an art exhibition (especially one that has at least some contemporary art in its collection) may be interested in an Immersive Scholar project because it can display data as art; the aim is not to learn about the actual data or the topic, necessarily, but about how it is displayed visually. Alternatively, a science museum may be interested in an Immersive Scholar project because of the topic of the data, in which the aim is to teach visitors about the data and the immersive display supports this learning experience. Essentially, the museum's mission should align.

As museums prioritize the visitor experience, digital formats require museums to rethink the visitor journey. Digital formats can be presented among physical objects in a phyiscal museum, as interactive supplemental tools such as apps to support the overall exhibit, or as digital exhibitions online. Whatever the choice, it needs to fit within the culture and the values of the community. In each exhibited object, museums want to evoke emotional reactions, provide educational or interpretive outcomes, encourage shared experiences with other visitors, and draw in audiences. Therefore, to create exhibitions that will generate interest in the collections, thought is put into how a user experiences the exhibition as a wholea thesis is crafted with an argument that ties all the chosen objects or works together. 
Some institutions have developed digital formats to encourage particular audiences to utilize their collections online. Initiated due to the travel bans of COVID-19, many museums in Europe sought digital solutions to engage their public with content, social media, and video concerts. Europa Nostra set up the Europa Nostra Digital Agora online platform (https://sites.google.com/europanostra.org/agora/), funded by the Creative Europe Programme of the European Union, to link to numerous cultural heritage sites' digital exhibits. One example is a Virtual Reality app tour, launched between the Anne Frank House, Force Field VR, and Oculus. Another example is the creation of the nextmuseum.io platform (https://www.nextmuseum.io/), launched between the NRW-Forum Duesseldorf / Kunstpalast Duesseldorf and Museum Ulm, which allows interested artists and curators to submit their multimodal digital works in an open exhibit call, and through swarm intelligence, accepted exhibits are selected and presented with a curatorial statement. Nextmuseum.io also incorporates calls for prototypes of experimental exhibition approaches to develop new digital audience engagement formats.

\section{Exhibition documentation}

To counter the ephemerality of exhibitions, exhibition catalogs are a way to preserve the experience by documenting what was included in the exhibit and incorporating supplemental materials like essays. The Getty Foundation has set up an Online Scholarly Catalogue Initiative (OSCI; https://www.getty.edu/publications/osci-report/) to help museums create digital versions of collection catalogs, which are easier to update, cheaper to produce, and expands readership. These catalogs are a way for museums to share research findings about materials in their collection, and to let audiences interact and engage with the content. It does this by setting up a space for peer institutions to pass advice about challenges and solutions to developing online publishing infrastructures. Six years after OSCI initiated, it was no longer a question of how scholarly digital collection catalogs brought value, but rather how best to publish them - challenges, recommendations, and discussion of evaluation of which are described further in Albers (2017). As a participating museum, Tate Museum has set up a Research Publications page, with The Camden Town Group in Context (https://www.tate.org.uk/art/researchpublications/camden-town-group/contents-r1106518) as a publication that can be explored. This publication includes an introduction to the project, a list of contributors involved, acknowledgements, art entries, artist biographies, and a variety of written essays about the exhibition contents. Notably, amidst the list of contributors are a publication team that would enable technical and aesthetic quality of the digital catalog publication and an editorial board that would review the quality of the publication. Museum publishers are also thinking about discovery, longevity, and objectness (as mentioned in the "Background" section) in their digital catalogs. The depiction of an Immersive Scholar project in a museum catalog would necessarily be a different, more static experience for a reader compared to a patron in the exhibition. The goal in including a preserved version is consequently to give a sense of longevity to the artist's credit of having gotten their work into an exhibit. This documented version can give a sense of proof of impact to the tenure committees.

\section{Challenges}

Incorporating digital format materials into the collection or an exhibition can be challenging for museums due to a lack of staff time, networking and systems level expertise, and hardware technology. Resultingly, digital immersive experiences are much less likely to become traveling exhibitions. Museums with digital works typically have bespoke interactive immersive experiences because hardware and room dimensions are so particular to the museum. Especially at smaller museums, to avoid these challenges may require 
additional support. COVID-19 has already caused museums to reconsider their digital role, especially since it needs also to consider addressing equity and accessibility issues.

Museums have had trouble adjusting to their digital role. Many museums consider digital works to distract from the rest of a physical exhibit, because it unfairly draws attention to itself, and often do not prefer to create wholly digital exhibitions. It will be important to draw a balance, to adapt narrative into technology for small audiences in ways that can scale to reach more people over time, such as The Stranger Disease (http://www.goatintheroadproductions.org/stranger-disease-press-packet; Voss, 2020). Still, the first objective remains identifying how to get people physically into the museum. Currently, the physical experience is not meant to be translated into a digital format; rather, a museum's interaction with digital formats is meant to be applied based on what they have learned already.

\section{Publishing}

Due to Immersive Scholar's existence as an academic work, we have considered it as a potential publishing opportunity. Various aspects of each project (such as its generative displays to illustrate concepts, or its collection of data, or its process of analyzing and interpreting the data using distinct softwares) could be used to expand scholarship for others; and disseminating the full range and value of scholarly research is the core goal of university presses. Publishers have a unique ability to grant authority and reach to scholarly works so that policymakers, opinion leaders, nonprofits, journalists, and scholars can discover and build upon the knowledge. If university presses were to become partners, the visual output (or at least a static capture of one instant's output) and the supplemental productive works would be associated as a product within the press's list.

Publishers provide "careful editorial development; professional copyediting and design; extensive promotion and discoverability efforts; and global distribution networks" in order to curate the scholarship to its best form, and format objects that can be engaged with (American Association of University Presses, 2019). Optionally, they can hire a Development Editor if deemed necessary to put more effort into the development and structure of the content. Adding a Development Editor to an Immersive Scholar project may be an additional way to reduce librarian time and labor to the creation of the work. The fee for the Editor would need to be considered in the project's budget. These services provide many features that Waters (2016) and Albers (2017) brought up in the "Background" section of this report, most notably pertaining to objectness and discoverability.

Here are a few examples of publisher-supported digital scholarship that is not primarily digital text:

- Berg Fashion Library (https://www.bloomsbury.com/dr/digital-resources/products/berg-fashionlibrary/), is a digital resource hosted on the "Bloomsbury Fashion Central platform" maintained by Bloomsbury and previously by Oxford University Press includes ebooks and images from museum collections and museum exhibitions.

- Yale University Press created the A\&AePortal online resource (https://www.aaeportal.com/), which is meant to feature scholarship in history of art, architecture, decorative arts, photography, and design. Emphasizing out of print, backlist, frontlist, and (peer reviewed) born-digital subject specific ebook collection, it also includes a database of images that appear in the ebooks. Their rich use of metadata encourages discoverability of similar items within the portal. University 
press and museum publishers included within the portal's collection are listed on https://www.aaeportal.com/ebooks/publishers.

- Social Explorer (https://company.socialexplorer.com/) is a geospatial dataset and visualization platform maintained and run by the Social Explorer organization, and was previously distributed from 2010-2019 as a digital product by Oxford University Press.

\section{Acquisition}

Publishers have to think about content fit, financial fit, and technical fit for any project proposal. They are deeply aware of their mission-when acquiring, they look to publish what subjects they specialize in, because those subjects are where they have expertise and credibility: they know the expert researchers in the subject area, they know the market, and they have content to build expertise upon already. A list of what subject area each university press publishes in is kept at https://aupresses.org/resources/aupressessubject-area-grid/. Publishers are thus acquiring proactively-does this fill a gap within what we want to publish, rather than should we publish this? Besides content fit, they have to check that their financial model can support the work. University presses are nonprofit publishers, funded only in small part by their corresponding institution and expected to return profit back to the university. Besides an annual university stipend, their spending must be self-sufficient, so a price (if any) is allocated to a product and a number of copies or subscriptions are estimated to help evaluate whether they can afford to acquire and begin work on the project. Part of the spending for that product could be technical or user experience work for digital compatibility and copyediting for professional aesthetics.

Publishers consider any project that comes to them, even if already fully working, to be considered a draft — which will be put up for peer review and potentially need revisions before ready for publisher involvement. Considering the time required to create an Immersive Scholar project, it would be best to begin conversations with the publisher early to tease fit. Also, for the Immersive Scholar projects to fit into this model of acquisition, outlining the purpose and scope, projecting potential projects, and approving an Immersive Scholar series, for at least a limited number of titles, would be a first step. This way, either solicited or unsolicited, the acquisitions already are folded into the press's mission, rather than trying to unconvincingly tack on a random project. Many university presses must receive approval for all publications from a higher review board (e.g., UNC Press has a Board of Governors, Oxford University Press has Delegates) that checks whether the acquisition is sufficiently scholarly.

Once published, an individual work is considered to be finite. Any further updating could be published separately as a second or "expanded" edition. As Sara Cohen, Senior Acquiring Editor at University of Michigan Press explained, many authors want to include everything at once, which is too complicated and long for a book experience, so scaling is really important. If the author wants to add more later, it could be added later in a new edition. Typically with a new edition, the previous edition is replaced and made out of print. With digital scholarship, however, if the project's analysis is based on an initial set of collected data, and later a new analysis uses an updated set of collected data, there could be an argument to keep both editions open "in print" so long as each edition is clearly marked to avoid confusion.

\section{Infrastructure}

When considering the technical fit for a product, a publisher could place it on a platform they [rarely] already own, develop or co-publish it using a digital platform maintained from another publisher (like 
Fulcrum or Manifold), create a [expensive] custom platform for it, or link to it from a platform the author identifies. If the publisher already has a platform for digital scholarship, the editor can next think about whether the project can fit the criteria within the platform's capability. The platform will already have established objectness rules that can be automatically applied, and the product will appear standardized (which can be good for brand recognition or bad for noncompliant specs). Though possible to adjust the platform, any tweak to the platform should have multiple future benefits rather than just meeting a single project's needs. Also, because they own the platform, they have the freedom (and the burden) of having staff to maintain it for needed updates. Depending on the requirements of the digital project, a publisher could technically post the project's record page on their website as a landing spot, that could then link to separate locations. Publishing on a third party platform, such as Scalar, may fit the particular project's needs, but if Scalar were to update or stop being supported, the project could fall apart, and that uncertainty of content quality makes publishers uncomfortable. University of Michigan Senior Acquiring Editor Sara Cohen described an upcoming project that uses hip hop music to perform scholarship: to do this, the project could be housed on the Fulcrum publishing platform, link to a playlist of hip hop music files on Bandcamp, include an introductory essay and several PDF articles, and provide an EPUB/PDF of liner notes. The scholarly emphasis is on the ability and ease of listening to the physical music, so Bandcamp was determined to be the best platform to fit their needs in this case. An Immersive Scholar is primarily nontextual, so many of the currently developed publisher platforms such as Fulcrum are likely not obvious initial choices for technical fit. Svensson (2016) states, "When new generations of infrastructure are based on traditional infrastructures, we have to be sensitive to the complexities and changing dynamics of those traditional infrastructures." There can be resistance to considering how to publish a work like Immersive Scholar when already so many difficult factors are involved in switching from print to digital in a traditional monograph processes, infrastructure, and strategic models.

\section{Discoverability}

Projects gain reach under publishers because publishers have processes that make the product discoverable. Publishers submit records to various different access points because this increases the number of chances that it will match where a person conducts research. The product is also linked on the publisher's website, which gains authority over time in search engines because so much traffic is coming to the publisher's website overall. This benefit will only work if all of the project's components are in one place. Additionally, the publisher's platform is supported; there is someone at the publisher who is in direct contact with Google Scholar, and other index vendors, to ensure links between these are working and the content is discoverable. Three major discovery vendors publishers submit content to for library searching is ProQuest, EBSCO, and OCLC. Depending on the publisher, they will have someone who tags the content, and the website, for search optimization. Otherwise, they will have to pay a cataloguing house service like OCLC to create MARC records for them-Immersive Scholar products may profit from improved metadata tagging if the associated library host's metadata librarian can do this instead.

A publisher's branding should be standardized, even if it begins to adapt. Amongst a publisher's services is marketing the product, for instance at conferences. If a product does not match the subject specialties of the publisher, this could decrease their capacity to market the product - they do not have the means to attend a conference for one book, nor do they have the recognition in that field to associate the book with quality. Also, brand helps to define the product: as a digital publication, it must be easy enough to explain for audience members to be able to recognize it. For example, a book series should recognizably appear 
similarly for it to be associated within the same series; despite Duke University Press's Project Euclid math database filling conceptually many separate roles, it could be explained as a platform, which includes various math scholarship.

\section{Challenges}

For scholars to trust in initiating an Immersive Scholar project with the goal of its publication, many university presses will likely need to be interested in participating. Publishers assume they need to have an appropriate platform before they can try publishing digital scholarship, because otherwise they fear they cannot reliably market and maintain perpetual access for their publication. Duke University Press published one issue of its American Literature journal on the Scalar platform (https://read.dukeupress.edu/american-literature/issue/85/4). The journal editor wanted to do this special issue on the Scalar platform because it would fit that issue's theme of new media. However, the editor found it more difficult than usual to receive submissions for that issue because they did not know how to use Scalar. The abstracts were put on the journal issue's catalog page on the Duke's website, and then the content for the issue was on the Scalar site; reportedly, the issue didn't get much usage and attention, and it wasn't tried again.

Publishers are finding that usage statistics are collected and reported differently depending on the discovery service, which makes combining overall use data incomplete and inaccurate.

Publishers also expect to face discovery challenges for untraditional works in regards to metadata schema and unexpected discovery sources that the intended audience might prefer. To be added into a library catalog, the information is limited to the confines of a MARC record; to be sent to a discovery service, the standard metadata standard will likely not well describe the untraditional nature of the work. To submit the most descriptive information about Immersive Scholar projects as well as find relevant discovery services, try to match the metadata schema used for art installations, and to submit the Immersive Scholar projects to such abstract/index services that focus on art installations. Otherwise, it is even possible to contact a vendor to ask for advice about how to describe the material.

Publishers are currently inconsistent about their involvement in accessibility. Even if some publishers view this as a priority, and follow accessibility standards for the product on their own website, the vendor they send the product to may not. Especially with the increased priority of social justice among funders, and library policies beginning to require ADA compliance for services to which they subscribe, incorporating ADA compliance from the beginning would be an asset for Immersive Scholar products. To help move forward with this, follow a VPAT - a checklist that will help know what to prioritize.

\section{Preservation}

Digital scholarship projects are naturally unwieldly. They have a lot of files that make up their composition, and they require software to run. It could be easy enough for analyzed data that makes up the immersive visualization output to fall out of date, let alone for the physical or digital technology to antiquate or break. Detailed below are several examples of digital scholarship projects with comments about their sustainability: 
- EPFL Digital Humanities Laboratory (DHLAB), directed by Frederic Kaplan, has created the Venice Time Machine to model the evolution of Venice over 1000 years. His work got sent to exhibitions in several museums including the Biennale of Architecture in Venice and the Museum of Modern Art in New York. To create the work, he collaborated internationally with the Ca'Foscari University in Venice and the Venice State Archives, as well as joined a steering committee that involves over 200 institutions. Yet as of September 2019, it has been suspended due to disagreements among partners about how to handle open data and methodology due to a lack of contractual details (https://www.nature.com/articles/d41586-019-03240-w). If a project is halted or ended, this brings up questions such as what happens with the files that take up space and how to recover if documentation had not been kept. Learning from what has halted previous projects can help prepare and sustain new projects.

- MedArt, a 2016 NEH funded project through University of Pittsburgh, was a digital collection of medieval art placed on a website. Once created, it became very popular but then began to be updated; a sustainability plan was set up to pursue digital preservation of an impactful digital product (Langmead et al, 2018).

- Fulcrum, a publishing platform created by University of Michigan Press (funded by Mellon) with preservation support from the University Libraries, is hosted on the University Library's servers. This decision was made during initial strategic planning, because the planning team held durability through the preservation of content as one of Fulcrum's core values. More details about the preservation process can be found on Fulcrum's website (https://www.fulcrum.org/preservation/).

- Slave Voyages https://www.slavevoyages.org/ includes data, essays, video of a $3 \mathrm{~d}$ model, maps, and also has an opportunity for viewers to contribute data. The site is currently sustained by Emory's Center for Digital Scholarship, though it will shift in 2020 to being maintained by a steering committee from approximately six recruited institutions. This decision would allow the project's publisher to "strengthen the site's organizational base, widen the pool of expertise on which we draw, and ensure a diverse and inclusive administrative structure." Responsibilities for sustaining this existing project would include approving additional developments, editing data contributions, responding to user queries and daily technical tasks, and meeting about audience and diversity strategic directions. The project would be hosted for six years on a circulating basis within the committee's participating institutions. Further information on the project's publication sustainability are described at https://www.slavevoyages.org/about/about\#news/10/informationrelease-on-the-future-of-slave-voyages/0/en/

- An early (2005) example from a university press of an interactive experience resembling a digital exhibit (https://railways.library.ualberta.ca/) has evidently not been maintained: There are no records from the publisher's catalog, the contact person identified for the platform no longer works at the press, and the HTML/CSS appears very antiquated. To sufficiently produce this project with its necessary technical requirements would have required partnership between the press and other organizations as well as significant time and financial investment. This exemplifies Waters's point about the digital publishing feature "maintained and preserved in its digital form." The underlying software still works, but when is this no longer considered a quality piece of digital scholarship? How would the university press consider the value of producing this scholarly product? 
Not all digital projects upon initiation are intended to run forever. This is why in the "Evaluation" section above, impact has been likened to that of performative theatre-its immersive, aesthetically creative quality is intended to be ephemeral at best. As stakeholders such as museums, publishers, and university personnel committees (among others within Figure 1) have shown above, the capacity for scholarly longevity is an enormous benefit. Documentation is one way to allow for a preserved product life, if not for a fully functioning life. There are many recommended practices and methods to do so, for instance, "[W]e can save it component files and store them in a repository; we can crawl it and produce a web archive made of WARC files; we can emulate and host the project's original technological environment; but perhaps the most obvious way — one that has been used for similarly ephemeral art forms for millennia-is documenting it" (Mulliken, 2017). Though preservation may be the responsibility of another stakeholder, it is good to keep a documentation trail throughout the creation process and to initiate conversations about a sustainability plan for the work.

\section{Conclusion}

Immersive Scholar crosses values agreed upon by the American Association of University Presses, namely, "University Presses play a leading role in experimenting with and developing new platforms for delivering and engaging with scholarship; University Presses partner with campus libraries, digital humanities centers, and other university departments to advance non-traditional initiatives in scholarly communication" (American Association of University Presses, 2019). Efforts are already being made by university presses to collaborate with libraries, to build digital platforms and dynamic databases. Many of these efforts are strongly supported by grant funding. But in addition, progress happens because people are communicating. Immersive Scholar is an emerging genre of digital scholarship. It builds upon types of research that have been done before - social media and other data analyses, virtual reality and immersive large-scale visualizations, digital humanities and digital archives. It follows similar processes as that of building, preserving, and reproducing software. Because of its emphasis on aestheticism and data collection, it has the flexibility to cover interdisciplinary fields and emphasize social justice narratives. To complete a complete, rich product, stakeholders must combine their skills in rhetoric, design thinking, accessibility, and technological awareness. The goals of museums, university presses, data scholars, and university libraries already align; with experimentation, collaboration among key partners, and an eye to these shared goals, Immersive Scholar can find its place in the scholarly conversation. 


\section{References}

Albers, G. (2017). Bringing books online. Museums and the Web conference, Cleveland, OH. Retrieved from https://mw17.mwconf.org/paper/the-next-generation-of-online-publishing-building-onwhat-weve-learned-together/

American Association of University Presses. (2016). The AE's choices about why, when, and how to conduct peer review. Best Practices for Peer Review: AUPresses Handbook for Monograph Publishing. Retrieved at https://peerreview.up.hcommons.org/sections/section-1/

American Association of University Presses. (2019, June). The Value of University Presses. Retrieved from https://aupresses.org/the-value-of-university-presses/

Benzi, K. (2020, Sept 15). When data visualization and art collide with the humble org chart. Nightingale. Retrieved from https://medium.com/nightingale/when-data-visualization-and-art-collide-with-thehumble-org-chart-647a2df46c5c

Fitzpatrick, K. (2011, Sept 25). Do the 'risky thing' in Digital Humanities. Chronicle of Higher Education. Retrieved from https://www.chronicle.com/article/do-the-risky-thing-in-digitalhumanities/

Gilmore, A., Glow, H., \& Johanson, K. (2017). Accounting for quality: Arts evaluation, public value and the case of "Culture counts." Cultural Trends, 26(4), 282-294. Retrieved from https://doi.org/10.1080/09548963.2017.1382761

Jarreau, P. (2020, Feb 10). Why should scientists work with artists? Lifeology. Retrieved from https://lifeology.io/why-should-scientists-work-with-artists/

Jones, B. (2012). Data visualization: Clarity or Aesthetics? DataRemixed. [Blogpost] Retrieved from https://dataremixed.com/2012/05/data-visualization-clarity-or-aesthetics/

Langmead, A., Quigley, A., Gunn, C., Hakimi, J., \& Decker, L. (1018). Sustaining MedArt: The impact of socio-technical factors on digital preservation strategies. Retrieved from https://sites.haa.pitt.edu/sustainabilityroadmap/wpcontent/uploads/sites/10/2017/01/SustainingMedArt_FinalReport_Web.pdf

Levulis, J. (2016, May 4). The Clark and WCMA receive grants to examine, utilize technology in art. WAMC. Retrieved from https://www.wamc.org/post/clark-and-wcma-receive-grants-examineutilize-technology-art\#stream/0

Lieberman, M. (2018, July 25). One-stop shopping for (free) virtual reality content. Inside Higher Ed. Retrieved from https://www.insidehighered.com/digital-learning/article/2018/07/25/drexeluniversity-introduces-repository-virtual-reality-assets 
Lozano-Hemmer (2015, Sept 28). Best practices for conservation of media art from an artist's perspective. Retrieved from https://github.com/immersive-scholar/Best-practices-forconservation-of-media-art

McCarthy, E. (2019). Developing digital audience frameworks for Oxford's GLAM. Performance Measurement and Metrics, 20(3), 179-85. Retrieved from https://doi.org/10.1108/PMM-09-2019$\underline{0042}$

Mulliken, J. (2017, Sept 12). Capturing the ephemeral. SUPDigital. Retrieved from http://blog.supdigital.org/capturing-the-ephemeral/

Rutgers University. (n.d.) Criteria for Tenure and Promotion. Visual, Media, and Performing Arts. Retrieved from https://vmpa.camden.rutgers.edu/faculty/tenure-and-promotion/

Svensson, P. (2016). Big Digital Humanities: Imagining a Meeting Place for the Humanities and the Digital. Digital Humanities. Ann Arbor: University of Michigan Press. Retrieved from http://dx.doi.org/10.3998/dh.13607060.0001.001

University of South Florida. (n.d.). Criteria for Promotion and Tenure. Retrieved from https://www.usf.edu/arts/administrative-resources/documents/tenure-promotion/sotd-tpguidelines.pdf

Voss, J. (2020, May 5). Redesigning libraries, archives \& museums post-COVID-19 2020. Retrieved from https://medium.com/community-archives/redesigning-libraries-archives-museums-postcovid-19-b85bcc9eaae1

Waters, D. J. (2016). retrieved from https://mellon.org/shared-experiences-blog/monograph-publishingdigital-age/

Williams, G. (2017, Sept 12). Are artists the new interpreters of scientific innovation? The New York Times Style Magazine. Retrieved from https://www.nytimes.com/2017/09/12/tmagazine/art/artist-residency-science.html 


\section{Appendix: Interview Questions}

Ten interviews conducted between June-September, 2020 for approximately thirty minutes each. Interviewees were selected with relevant diverse job titles across the Immersive Scholar ecosystem--from university presses in editorial, marketing, and production; from libraries in digital scholarship reference and metadata; from museums and in exhibition creation and educational and user experience services; and from universities in faculty leadership. Only those interviewees who permitted acknowledgement have been cited by name throughout as needed.

The following are examples of the types of questions asked and expanded upon, depending on the stakeholder focus.

\section{Acquiring}

1. What sort of things do digital humanists want in a publication? What does the infrastructure have to include.

2. How do you determine fit for digital projects that come to you?

3. When you're considering fit, how do you also think about interoperability?

4. Is there any possibility of a paying model for digital projects?

5. For peer review, what would you expect to be an adequate structure for reviewers? What sort of things are they reviewing for? How does this meet peer review standards?

6. (Museum) How might a large museum versus a local museum come into contact or be interested in new types of digital formats?

7. (Museum) What kind of staff role creates digital exhibitions? Or do you know of any museums that are collecting digital art?

8. (Museum) Does COVID increase museum motivation to do more digital exhibitions?

\section{Collaborating}

9. Faculty are creating innovative types of research, where do you see the press interact in the creation of the digital work (pre-handover)?

10. How much work can we (libraries) do supporting a digital project to increase your ability to work with us?

11. How have you previously worked with the library or other partner to create, or preserve, content? What were your roles? Did the final product have an ultimate owner? Would it be of interest to partner like this again?

12. What workflow process or value proposal might a university press have to undergo to get funding or support from its parent organization about piloting a new digital initiative?

\section{Technical Boundaries}

13. What has seemed possible for the academic publisher to get involved in for digital dissemination?

14. Where could the final product go? (Platform, server)

15. What digital architecture is in place for creation, preservation, and sharing of material?

16. What investment in digital architecture had to occur to make digital changes so far?

17. What is the extent that publishers get involved in a type of media format that other publishers have done? 
18. What would make discoverability for digital projects possible? Would it fit into discovery services? How technically does tagging affect discoverability?

19. (Museum) How do GLAM set up both physical and digital exhibitions?

20. (Museum) How do GLAM pass on material to other museums?

\section{Production}

21. How has production workflow been modified to fit the needs of a digital project?

22. What are some things that you were involved in related to accessibility?

\section{Preservation}

23. What is a publisher's role in the preservation and sharing of material? The library's?

24. What is maintenance like? Would this be considered a new edition, or automatically maintaining a backlist item?

25. How sustainable is this platform work after the grant ends?

\section{Impact}

26. What does it mean to license, and track usage, and market digital work?

27. How much standardization in branding would a publisher prefer in its digital format works?

28. How do you prove the quality and impact of digital work that's untraditional?

29. (Museum) How do GLAM emphasize description about the material displayed?

30. (Museum) What sort of audience engagement is there, especially in innovative works?

\section{Personnel Committee}

31. What is the process involved in reviewing a tenure portfolio? Is there a difference in the process and evaluation criteria of the university at large vs the department?

32. How often do you revise the evaluation criteria and why?

33. What are deemed to be impactful formats and which audiences are faculty in your department targeting?

34. How is the level of openness to Untraditional works at your department?

35. Is there anything particular about your department's culture that would make this dept more open to untraditional works than others? 